\title{
Effect of Maternal Nutrition and Dietary Habits on Preeclampsia: A Case-Control Study
}

\author{
Mulualem Endeshaw1, Fekadu Ambaw ${ }^{2}$, Amanu Aragaw ${ }^{3}$, Asrat Ayalew ${ }^{1}$ \\ ${ }^{1}$ Rift Valley University, Bahir Dar Campus, Bahir Dar, Ethiopia \\ ${ }^{2}$ Alkan University College, Bahir Dar Campus, Bahir Dar, Ethiopia \\ ${ }^{3}$ Bahir Dar Health Science College, Bahir Dar, Ethiopia \\ Email: emulualem@gmail.com, fekaduambaw14@gmail.com, amanuaragaw@yahoo.com, \\ asratayalew@yahoo.com
}

Received 27 October 2014; revised 26 November 2014; accepted 5 December 2014

Copyright (C) 2014 by authors and Scientific Research Publishing Inc.

This work is licensed under the Creative Commons Attribution International License (CC BY). http://creativecommons.org/licenses/by/4.0/

(c) (i) Open Access

\section{Abstract}

Introduction: Preeclampsia is one of the most commonly encountered hypertensive disorders of pregnancy that accounts for $20 \%-80 \%$ of maternal mortality in developing countries, including Ethiopia. For many years diet has been suggested to play a role in preeclampsia. However, the hypotheses have been diverse and often revealed inconsistent results across studies. Moreover, rarely were these hypotheses studied in Ethiopia. Therefore, this study aimed to explore whether the incidence of preeclampsia was related to nutrient or micronutrient deficiencies. Objectives: To describe the effect of nutrition and dietary habits on the incidence of preeclampsia. Methods: A facility based unmatched case-control study was conducted among 453 (151 cases and 302 controls) pregnant women attending antepartum or intrapartum care in public health facilities of Bahir Dar City Administration. Case-control incidence density sampling followed by interviewer administered face to face interview, measurement of mid-arm circumference (MUAC) and document review were conducted using a standardized and pretested questionnaire. Data entry and cleaning was done by Epi Info Version 3.5.3. The data were transported to SPSS Version 20 for analysis. Both bivariate and multivariate logistic regression analyses were applied. Backward stepwise unconditional logistic regression analysis was employed to determine the putative association of predictive variables with the outcome variable and to control for the effect of confounding variables. A $P$-value $\leq 0.05$ was considered statistically significant at $95 \%$ confidence level throughout the study. Result: Those women having a MUAC value $\geq 25.6 \mathrm{~cm}$ were two times more likely than their counterparts to have preeclampsia $(A O R=2.49,95 \% \mathrm{CI}=1.58,3.94)$. Strikingly, higher odds of preeclampsia were found in women who reported to have taken coffee during pregnancy $(A O R=2.16,95 \% \mathrm{CI}=1.32,3.53)$. Similarly, those women who had anemia during the first trimester pregnancy were three times more likely than their counterparts to have incidence of 
preeclampsia $(\mathrm{AOR}=2.80,95 \% \mathrm{CI}=1.09,7.21)$. The result in this study also revealed that taking fruit or vegetables during pregnancy was found to be protective of preeclampsia $(A O R=0.37,95 \%$ $\mathrm{CI}=0.19,0.73, \mathrm{AOR}=0.45,95 \% \mathrm{CI}=0.22,0.91$ ) respectively. In addition, folate intake during pregnancy has shown a significant independent effect on the prevention of preeclampsia in this study $(A O R=0.19,95 \% C I=0.10,0.37)$. Conclusion and Recommendation: Vegetable and fruit consumption and folate intake during pregnancy are independent protective factors of preeclampsia. On the other hand, higher mid upper arm circumference, anemia and coffee intake during pregnancy are risk factors for the development of preeclampsia.

\section{Keywords}

\section{Preeclampsia, Hypertension, MUAC, Anemia}

\section{Introduction}

Preeclampsia is defined as hypertension accompanied by proteinuria first detected after 20 weeks of gestation with or without generalized edema [1]. Preeclampsia is one of the most commonly encountered hypertensive disorders of pregnancy (HDP) [2].

Preeclampsia has remained a significant public health threat in both developed and developing countries contributing to maternal and perinatal morbidity and mortality globally [3]. Preeclampsia affects $5 \%$ to $10 \%$ of all pregnancies globally. The prevalence of preeclampsia in developing countries reaches up to $16.7 \%$ and it is estimated to account for about $40 \%$ to $60 \%$ of maternal deaths in developing countries [4]. WHO estimates the incidence of preeclampsia to be seven times higher in developing countries (2.8\% of live births) than in developed countries $(0.4 \%)$ [5].

Maternal morbidity remains great with preeclampsia, which continues to be one of the leading causes for the admission of pregnant women to intensive care units in the world [6]. It is also associated with significant maternal mortality, accounting for about 50,000 deaths worldwide annually [7]. Ninety-nine (99\%) percent of these deaths occur in the developing world which includes Ethiopia [8].

Studies showed that preeclampsia was associated with higher rates of pre-term delivery, caesarean section, small for gestational age babies, stillbirth and lower baby birth weight [7]. Fetal morbidity and mortality increase substantially in women with preeclampsia is a major cause of stillbirths and neonatal deaths [8] [9]. In addition, induction of women for delivery to prevent the progression of preeclampsia is responsible for $15 \%$ of all preterm births [10].

The onset of preeclampsia is only $5 \%$ from 20 weeks to 34 weeks of gestation, $90 \%$ from 34 weeks to labor and delivery, and the remaining $5 \%$ post partum within 48 hours after delivery [11].

In developing countries particularly in Sub-Saharan Africa where maternal services including prenatal care are limited, preeclampsia leads to high neonatal and maternal mortality [10].

In Ethiopia among the major five obstetric causes of maternal deaths, the proportion of maternal deaths due to severe preeclampsia or eclampsia shows increasing trend while that of abortion is decreasing and no grossly notable reductions in the proportions of maternal death in ruptured uterus, obstructed labor and sepsis are indicated [12].

A report from Felege Hiwot Referral Hospital (FHRH), the study area, indicated that the trend of preeclampsia was increasing in alarming rate. For example the trend from 2012 to 2013 was increased by 83\% without any change in the diagnosis and reporting system.

Despite the cause for preeclampsia is still obscure, there does appear to be certain risk factors which were identified by a number of studies, such as advanced maternal age [13], nulliparity [14], high maternal body mass index (BMI) [15], pre-existing hypertension [16], previous preeclampsia [17], renal disease [18], diabetes mellitus [19], gum disease [20], history of abortion [5], and sexual partner change before four months of pregnancy [13] [21]. Rural residence [18] has also been consistently reported as risk factors for the occurrence of preeclampsia. Some studies on the other hand revealed that maternal education, monthly income, physical exercise and singleton pregnancy to be protective factors for preeclampsia [14] [22].

Although the etiology of gestational hypertension and preeclampsia remains largely unclear, evidence sug- 
gests that the maternal diet is one of many factors suggested to play a role in the etiology of preeclampsia (The American Institute of Nutrition, 2009). Preeclampsia is characterized by metabolic disturbances similar to those found in cardiovascular diseases and type 2 diabetes mellitus (T2DM) including endothelial dysfunction, inflammation, oxidative stress, insulin resistance and dyslipidemia [23] [24]. Healthy diet characterized by high intake of vegetables, fruits and vegetable oils was associated with reduced risk of preeclampsia in women [25]-[27]. Dietary components and qualities associated with preeclampsia risk in observational studies include macronutrients, micronutrients, dietary fiber, alcohol, caffeine and individual foods as well as overall food patterns [28]-[30]. Trials aiming at preeclampsia prevention, however, have yielded mixed results [30]. While some evidences [30] promoted calcium intake, others found that homocysteine excess was a risk factor [31].

For many years diet has been suggested to play a role in preeclampsia. However, the hypotheses have been diverse and often revealed inconsistent results across studies. Moreover, rarely were these hypotheses studied in Ethiopia. Therefore, this study aimed to explore whether the incidence of preeclampsia was related to nutrient or micronutrient deficiencies.

\section{Methods and Materials}

\subsection{Study Design and Period}

A facility based unmatched case-control study was conducted among pregnant women attending antepartum or intrapartum care in public health facilities of Bahir Dar City Administration from June 2014 to September 2014.

\subsection{Study Area}

Bahir Dar City Administration is one of the three administrative cities and the capital of Amhara Region. Amhara Region is the second largest and populous regions in Ethiopia where close 20 million people are living. The city is located approximately $565 \mathrm{~km}$ northwest of Addis Ababa. According to Bureau of finance and economic development report, the city hosts a population of 277,566 with 0.92 male to female ratio. The city has one referral hospital and 5 health centers serving approximately 5 million people within and outside the city. The study involves all of these public health facilities found in the capital city of the region.

\subsection{Study Population}

All pregnant women attending antenatal care follow up and/or delivery during the study period at public health facilities of Bahir Dar City Administration, and meet the inclusion criteria.

Cases were pregnant women diagnosed to have any form of preeclampsia/eclampsia during ANC follow up, delivery care and postnatal within 48 hours by an obstetrician. Preeclampsia women were identified in they experienced blood pressure of 140/90 mmHg or higher at least twice with 4 hours apart after 20 weeks of pregnancy, as well as their urine lab result revealed protein excretion.

Control: A control was defined as a woman who gave birth during the preceding 2 days and who did not have a diagnosis of preeclampsia.

\subsection{Sample Size Determination}

The sample size was determined using Epi Info stat calc calculator for two populations by taking $85 \%$ power of the test, $95 \%$ confidence level and a control to case ratio of 2:1. Based on the above assumption, the total sample size required for case \& control including $10 \%$ for nonresponse was calculated to be 151 \& 302 respectively. An odds ratio of 2.3 was taken from the findings of literatures using age as a risk for preeclampsia [32].

\subsection{Sampling Technique and Procedure}

Pregnant women attending ANC or delivery care during the study period and fulfilling the inclusion criteria were recruited until the allotted sample was reached. We employed case-control incidence density sampling methods. That means, cases were enrolled consecutively as they are diagnosed to have preeclampsia/eclampsia until the required sample size was obtained. For each case, two controls were selected by using simple random sampling technique from the same health facility in the same day as soon as the cases are diagnosed. 


\subsection{Study Variables}

Presence of preeclampsia/eclampsia during pregnancy or delivery was the outcome variable, whereas maternal socio-demographic characteristics, dietary habits (fruit, vegetable, meat, alcohol, coffee and folate intake) and nutritional status [MUAC and anemia $(<11 \mathrm{~g} / \mathrm{dL})$ ] were taken to be independent variables.

Traditionally, BMI is used to measure nutritional status of women and classify pregnant women as underweight, normal, overweight, or obese. It is recommended that this index be calculated for all women using appropriate measurements, during the initial booking visit at about 10 weeks of gestation. However, pregnant women in the study area do not book early for antenatal care so, their actual weights at 10 weeks of gestation were not available. Thus, we used MUAC of the women to assess overweight and obesity but there is no reliable cut off points for diagnosis of overweight and obesity in the study area. Therefore, we used the average MUAC value of the respondents to determine the cutoff point and assess the risk of preeclampsia. Based on this, the cutoff point was set using the women's' average $(25.6 \mathrm{~cm})$ MUAC value.

\subsection{Data Collection Procedure}

Interviewer administered face to face interview, measurement of MUAC and document review were conducted using a standardized and pretested questionnaire. Ten midwives and two supervisors were recruited to collect the data after they received training with for one day.

\subsection{Data Management and Data Analysis}

All responses to the survey questionnaires were coded against the original English version and data entering, and cleaning was done through Epi Info Version 3.5.3. Then the data were transported to SPSS Version 20 for further data cleaning and analysis. Frequency run was made to check for accuracy, outliers, consistencies and missed values and variables. Finally the data were exported to STATA Version 12 for analysis of some selected variables. Model fitness was assessed using the Hosmer-Lemeshow goodness-of-fit and our model fits pretty well: $\chi^{2}=56.5$, $P$-value 0.71 .

Before carrying out the multivariate analysis, we assessed the possibility of multicolinearity between the covariates, in the correlation matrix of covariates, all pair wise Pearson correlation coefficients were $<0.5$, suggesting that multicolinearity did not affect the findings. Both bivariate and multivariate logistic regression analyses were applied. A $P$-value less than 0.05 considered statistically significant at $95 \%$ confidence level throughout the study.

Backward stepwise logistic regression analysis was employed to determine the putative association of predictive variables with the outcome variable and to control for the effect of confounding variables. All of the explanatory variables were entered into the model.

\subsection{Ethical Consideration}

Ethical clearance was sought from Bahir Dar University School of Public Health Ethical Review Board. The person in charge of each facility and care providers were informed and their agreement received before the onset of data collection. Moreover, all the study participants were informed about the purpose of the study, their right to refuse and assurance of confidentiality. Then, verbal consent was obtained from each study participant. Strict confidentiality assured through anonymous recording and coding of questionnaire.

\section{Results}

\section{Socio-Demographic Characteristics of Study Participants}

A total of 453 verbally consented pregnant women who came for either antenatal follow up or skilled delivery service were enrolled in this study. The mean age of the study participants was 27.14 years (range from 16 - 43 years) with SD of \pm 5.73 years. Two hundred seventy-seven (61.1\%) of the women came from urban residence and the rest (38.9\%) came from rural area. Out of 453 study participants, 193 (42.6\%) have no formal education. Four hundred twenty two women (93.2\%) were married. The median family monthly income of the study participants was 1500 Ethiopian Birr (range from 350 - 8500 ETB) and two hundred fifty eight (57\%) women have a monthly income below the median value. Most of the study participants were house wife (61.6\%) and the rest 
were employed (23.2\%) and merchants (15.2\%) (Table 1).

The bivariate analysis in this study revealed that several factors to be predictive of preeclampsia during pregnancy. Living in rural residence as compared to urban dwelling (COR $=1.53,95 \% \mathrm{CI}: 1.03,2.28)$, and advanced maternal age as compared to younger age (COR $=2.53,95 \% \mathrm{CI}$ : $1.16,5.54)$ were found to be determinants of preeclampsia in the bivariate analysis, however, the effect did not remain significant after adjusting for control of confounding. Similarly, women who reported to have drunken alcohol during the index pregnancy had an increased risk of preeclampsia as compared with those women who did not drink alcohol (AOR $=1.66,95 \% \mathrm{CI}=$ $1.12,2.46$ ) in bivariate analysis, but turned out to be insignificant when adjusted in the final model). Since the

Table 1. Socio-demographic characteristics of pregnant women attending antenatal follow up or delivery care in Bahir Dar City, Ethiopia, 2014.

\begin{tabular}{|c|c|c|}
\hline Variables & Number & Percentage \\
\hline \multicolumn{3}{|l|}{ Age } \\
\hline$<20$ & 57 & 12.6 \\
\hline $20-24$ & 99 & 21.9 \\
\hline $25-29$ & 159 & 35.1 \\
\hline $30-34$ & 76 & 16.8 \\
\hline 35 and above & 62 & 13.7 \\
\hline Total & 453 & 100 \\
\hline \multicolumn{3}{|l|}{ Residence } \\
\hline Urban & 277 & 61.1 \\
\hline Rural & 176 & 38.9 \\
\hline Total & 453 & 100 \\
\hline \multicolumn{3}{|l|}{ Marital status } \\
\hline Currently married & 422 & 93.2 \\
\hline Single $^{*}$ & 31 & 6.8 \\
\hline Total & 453 & 100 \\
\hline \multicolumn{3}{|l|}{ Occupation } \\
\hline Employed & 105 & 23.2 \\
\hline Merchant & 69 & 15.2 \\
\hline House wife & 279 & 61.6 \\
\hline Total & 453 & 100 \\
\hline \multicolumn{3}{|l|}{ Education } \\
\hline No formal education & 193 & 42.6 \\
\hline Primary & 54 & 11.9 \\
\hline Secondary & 122 & 26.9 \\
\hline Higher education & 84 & 18.5 \\
\hline Total & 453 & 100 \\
\hline \multicolumn{3}{|l|}{ Income } \\
\hline$<1500$ birr & 258 & 57 \\
\hline$\geq 1500$ birr & 195 & 43 \\
\hline Total & 453 & 100 \\
\hline
\end{tabular}

\footnotetext{
${ }^{*}$ Unmarried, divorced and widowed.
} 
association of preeclampsia with dietary pattern may be modified by other covariates, we further examined the risk estimate after entering to multivariate regression model. Hence, we entered variables that have $P$-value $\leq$ 0.2 in the bivariate analysis into multivariate analysis. The risk of preeclampsia was evident in both the crude and adjusted analysis for women who had high MUAC value and taken coffee and alcohol during pregnancy. Nevertheless, those women who had taken folate, fruit and vegetables were more likely to be protected from the incidence of preeclampsia.

Those women having a MUAC value $\geq 25.6 \mathrm{~cm}$ were two times more likely than their counterparts to have preeclampsia $(\mathrm{AOR}=2.49,95 \% \mathrm{CI}=1.58,3.94)$. Strikingly, higher odds of preeclampsia were found in women who reported to have taken coffee during pregnancy $(\mathrm{AOR}=2.16,95 \% \mathrm{CI}=1.32$, 3.53). Similarly, those women who had anemia during the first trimester pregnancy were three times more likely than their counterparts to have incidence of preeclampsia $(\mathrm{AOR}=2.80,95 \% \mathrm{CI}=1.09,7.21)$. The result in this study also revealed that taking fruit or vegetables during pregnancy was found to be protective of preeclampsia $(\mathrm{AOR}=0.37,95 \% \mathrm{CI}=$ $0.19,0.73, \mathrm{AOR}=0.45,95 \% \mathrm{CI}=0.22,0.91$ ) respectively. In addition, folate intake during pregnancy has shown a significant independent effect on the prevention of preeclampsia in this study $(\mathrm{AOR}=0.19,95 \% \mathrm{CI}=$ $0.10,0.37)$.

However, unlike other previous studies, factors such as education, marital status, monthly income and occupation of women did not show any significant correlation with the incidence of preeclampsia in our study (Table 2).

\section{Discussion}

To the best of our knowledge, this is the first report of a facility based case-control study to determine predictive factors of preeclampsia among women in Bahir Dar, Ethiopia. The findings of this study should be viewed in light of the following limitations.

We might have introduced selection bias since cases were selected consecutively as they appear for diagnosis. The random and systematic measurement error in self-reported dietary intake might attenuate the association observed in this study. Dietary assessment was made at diagnosis hence, recall bias is inevitable. We did not also assess the effect of wide range of dietary factors on preeclampsia; therefore, causal relationship cannot be inferred from this case-control study.

The main finding of this study was that women who reported eating vegetables or fruit had lower risk of developing preeclampsia than women who reported not consuming vegetables or fruit. This finding is consistent with the study conducted in Norway [25] [29] [30] [33] which revealed a reduced risk of preeclampsia with organic vegetable consumption. Several mechanisms for a biological effect of dietary behavior on incidence of preeclampsia may exist. Vegetables and fruits are rich in micronutrients such as antioxidants, vitamins, minerals, and dietary fiber. A diet rich in fruits and uncooked vegetables decreased the risk of hyperhomocysteinemia which is one of the risk factor for the occurrence of preeclampsia [34]. The result of this study revealed that adherence to dietary advice to consume a diet abundant in vegetables and fruit may be beneficial with regard to prevention of preeclampsia. However, other previous studies did not find a supporting evidence that self-reported intake of organic fruit prevent preeclampsia [35].

Consistent with previous studies [28] [36], we found that folic acid supplementation during pregnancy was associated with a lower risk of preeclampsia. Beside its crucial advantage of preventing neural tube defect in babies, folic acid supplementation during pregnancy has been thought to decreases plasma homocysteine concentrations [28] [37]. Homocysteine is an amino acid released as the body digests dietary protein. It has been shown that its level increases during preeclampsia and elderly. As indicated above, too much homocysteine in the blood is linked with a greater risk of heart disease, stroke and nerve damage [33]. Excessive homocysteine in pregnancy might damage the vascular endothelium of the developing placenta by promoting oxidative stress thereby increasing contractile response and the production of procoagulants and vasoconstrictors which lead to development of preeclampsia [34]. Although we did not explore further about the dose and compliance of folate intake, its use by itself might have contributed for the prevention of preeclampsia in this study. This finding underscores the need for continued promotion of universal provision of folate for all pregnancy women. However, other few studies revealed that taking folate would lead to childhood asthma [38].

In the present study, we were able to empirically assess the effect of nutritional status on preeclampsia. Although maternal Body Mass Index (BMI) has been evaluated as a good marker of preeclampsia in previous 
Table 2. Result of bivariate and multivariate analysis of covariates with incidence of preeclampsia, Bahir Dar City, October, 2014.

\begin{tabular}{|c|c|c|c|c|c|c|}
\hline \multirow{2}{*}{ Variables } & \multicolumn{2}{|c|}{ Preeclampsia } & \multirow{2}{*}{ COR $(95 \%$ CI $)$} & \multirow{2}{*}{$P$-value } & \multirow{2}{*}{ AOR $(95 \% \mathrm{CI})$} & \multirow{2}{*}{$\begin{array}{c}P \text {-value } \\
\text { adjusted }\end{array}$} \\
\hline & Yes (\%) & No (\%) & & & & \\
\hline \multicolumn{7}{|l|}{ Age } \\
\hline$<25 \mathrm{yrs}$ & $63(30.0)$ & $147(70.0)$ & 1 & \multirow{3}{*}{0.028} & \multirow{3}{*}{$\dagger$} & \\
\hline $25-34$ yrs & $60(33.1)$ & $121(66.9)$ & $1.15(0.75,1.77)$ & & & \\
\hline$\geq 35 \mathrm{yrs}$ & $28(45.2)$ & $34(54.8)$ & $1.92(1.07,3.4)$ & & & \\
\hline \multicolumn{7}{|l|}{ Residence } \\
\hline Urban & $82(29.6)$ & $195(70.4)$ & 1 & \multirow{2}{*}{0.035} & & \\
\hline Rural & $69(39.2)$ & $107(60.8)$ & $1.53(1.03,2.28)$ & & + & \\
\hline \multicolumn{7}{|l|}{ Marital status } \\
\hline Married & $141(33.4)$ & $281(66.6)$ & 1 & \multirow{2}{*}{0.895} & & \\
\hline Single & $10(32.3)$ & $21(67.7)$ & $0.94(0.44,2.10)$ & & & \\
\hline \multicolumn{7}{|l|}{ Occupation } \\
\hline Employed & $33(31.4)$ & $72(66.6)$ & 1 & \multirow{3}{*}{0.511} & & \\
\hline Merchant & $25(36.2)$ & $44(63.8)$ & $1.24(0.65,2.35)$ & & & \\
\hline House wife & $93(3.3)$ & $186(66.7)$ & $1.09(0.67,1.77)$ & & & \\
\hline \multicolumn{7}{|l|}{ Education } \\
\hline Unable to read \& write & $50(36.2)$ & $88(63.8)$ & $1.54(0.88,2.7)$ & \multirow{2}{*}{0.286} & $2.34(1.2,4.62)^{*}$ & 0.014 \\
\hline Able to read \&write & $101(33.1)$ & $214(68.0)$ & 1 & & 1 & \\
\hline \multicolumn{7}{|l|}{ Income } \\
\hline$<1500$ birr & $88(34.1)$ & 170 (65.9) & $1.09(0.73,1.61)$ & \multirow{2}{*}{0.691} & & \\
\hline$>1500$ birr & $63(32.3)$ & $132(67.7)$ & 1 & & & \\
\hline \multicolumn{7}{|l|}{ MUAC } \\
\hline$<25.6 \mathrm{~cm}$ & $101(28.3)$ & $256(71.7)$ & 1 & & 1 & \\
\hline$\geq 25.6 \mathrm{~cm}$ & $50(52)$ & $46(48)$ & $2.76(1.74,4.43)$ & 0.004 & $3.26(1.94,5.5)^{*}$ & 0.001 \\
\hline \multicolumn{7}{|l|}{ Fruit intake } \\
\hline Yes & $92(27.1)$ & $247(72.9)$ & $0.34(0.22,0.54)$ & \multirow{2}{*}{0.001} & $0.37(0.2 .0 .73)^{*}$ & 0.020 \\
\hline No & $59(51.8)$ & $55(48.2)$ & 1 & & 1 & \\
\hline \multicolumn{7}{|l|}{ Vegetable intake } \\
\hline Yes & 105 (28.3) & $266(71.7)$ & $0.31(0.19,0.50)$ & \multirow{2}{*}{0.001} & $0.45(0.22,0.9)^{*}$ & 0.007 \\
\hline No & $46(56.1)$ & $36(43.9)$ & 1 & & 1 & \\
\hline \multicolumn{7}{|l|}{ Meat intake } \\
\hline Yes & $143(37.7)$ & 281 (66.3) & $1.34(0.58,3.10)$ & \multirow{2}{*}{0.411} & & \\
\hline No & $8(27.6)$ & $21(72.4)$ & 1 & & & \\
\hline \multicolumn{7}{|l|}{ Coffee intake } \\
\hline Yes & $124(38.5)$ & 198 (61.5) & $2.41(1.49,3.90)$ & 0001 & $1.82(1.1,3.14)^{*}$ & ברחקר \\
\hline No & 27 (20.6) & $104(79.4)$ & 1 & 0.001 & 1 & 0.002 \\
\hline Folate intake & & & & & & \\
\hline
\end{tabular}




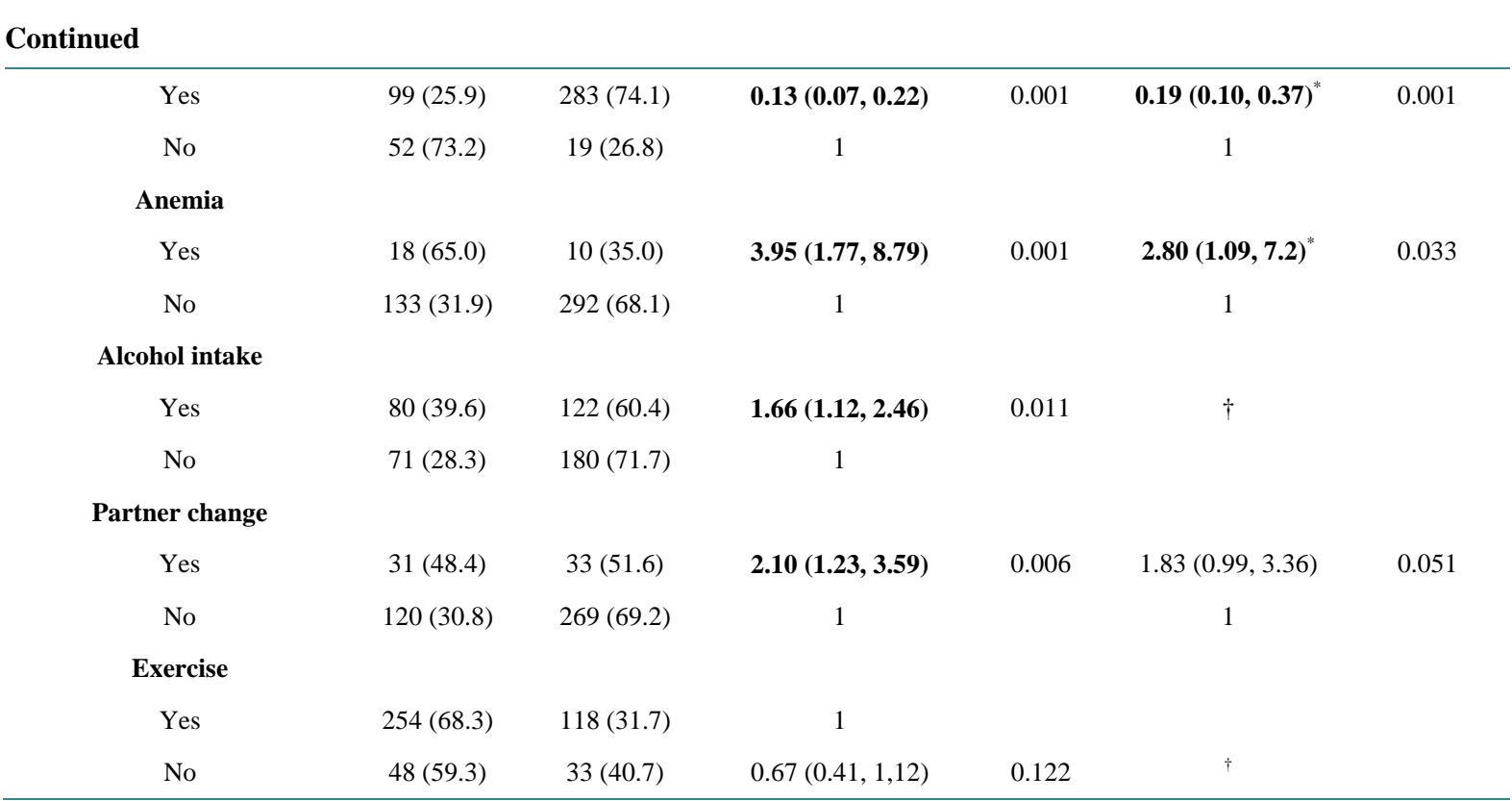

${ }^{\dagger}$ Dropped in the final model; * Statistically significant at 95\% CI and $P$-value $\leq 0.05$ : adjusted for maternal age, residence, MUAC value, fruit and vegetable intake, folate intake \& anemia.

studies [39], the pregnant women in this study did not book early for antenatal care, hence, their actual weights at 10 weeks of gestation were not available. As maternal Mid-Upper Arm Circumference (MUAC) is considered to be relatively stable during pregnancy among women of developing countries [40] we used MUAC measurement instead. There were linear trends in risk of preeclampsia with increasing mid-arm circumference in this study. Women who had a MUAC value above the average $(25.6 \mathrm{~cm})$ had two fold increased risk of preeclampsia compared to women in the lower value MUAC $(\mathrm{AOR}=2.49,95 \% \mathrm{CI}=1.58,3.94)$. This finding is consistent with studies conducted in Zimbabwe [40] [41] and UK [41]. These studies have shown that higher values of anthropometric measurements are related to obesity and are useful in predicting preeclampsia risk. However, using MUAC and BMI as an independent marker for predicting preeclampsia has been criticized as fairly weak methods in recent studies [15] [41]. Other studies [42] also propose the use of body fat mass and total body water measurement as reliable methods to predict risk of preeclampsia in pregnancy than MUAC or BMI indices.

The prevalence of anemia $(<11 \mathrm{~g} / \mathrm{dL})$ in this study was $6.2 \%$ and no woman was registered as having severe anemia $(<7 \mathrm{~g} / \mathrm{dL})$ when the baseline hemoglobin value is measured during the first trimester antenatal care booking. The authors do not have plausible reasons to explain why the prevalence of anemia is low in this study as compared to the findings in developing countries [43]. As a matter of fact Iron deficiency anemia is the most common types of anemia in pregnancy [44].

In agreement with other studies [44] [45], the finding in our study has shown that those women having anemia during the first trimester were almost 3 times more likely than who did not to have increased incidence of preeclampsia. The susceptibility of women with anemia to preeclampsia could be explained by a deficiency of micronutrients and antioxidants. Recent results also indicate that reduction in serum levels of calcium, magnesium and zinc during pregnancy might be possible contributors to the development of preeclampsia [30]. The occurrence of anemia in this study might be related to a reduced intake of fruit and vegetables and other micronutrient deficiency. Strikingly, however, other studies [45] demonstrated the risk of highest hemoglobin concentration to predispose to preeclampsia; a reduced plasma volume might attribute to the observed result.

The result of this study also showed that coffee intake during pregnancy has statistically significant association with incidence of preeclampsia. This finding is consistent with other studies [46]. The study in Norway revealed that higher caffeine (coffee, tea) intake during pregnancy seems to be associated with elevated systolic blood pressure levels in first and third trimester pregnancy. Caffeine intake acutely increases blood pressure levels. Habitual caffeine consumption may be associated with chronic blood pressure levels or the risk of hypertension in non-pregnant adults. The mechanisms by which caffeine exposure affect heart rate and blood pressure levels might include increases of catecholamine levels, which might subsequently lead to vasoconstriction. Dif- 
ferences in blood pressure levels associated with caffeine intake during pregnancy might be markers of subclinical cardiovascular adaptation mechanisms and the subsequent risk of hypertensive complications, such as pregnancy-induced hypertension and preeclampsia [29] [47]. On the other hand, other studies reported that caffeine intake prevent incidence of hypertension during pregnancy [48]. However, others did not find any evidence whether caffeine intake affects blood pressure during pregnancy or not [47].

In agreement with the results of previous studies [32] there was no significant relationship between maternal age and preeclampsia in this study. However, it was different from the results observed by other study [49] that observed the relationship between advanced maternal age and occurrence of preeclampsia. Such difference could be due to the variation of study designs and study settings. Rural residence has been identified as a risk factor for preeclampsia in several studies [50]. However; we observed only a weak positive association of preeclampsia risk with this covariate in the bivariate analysis.

Unlike other previous studies [51], the result of this study showed no statistically significant association between alcohol intake during pregnancy and incidence of preeclampsia. This possible explanation for this variation may be the difference in the type of alcohol being taken, the amount and the frequency of drinking. Residual confounding, due to insufficient or unmeasured lifestyle habits, might be involved. Nonetheless, our finding is in line with other findings [52].

Previous studies have reported sexual partner change as a risk factor for preeclampsia [13] [21]. This current study did not find change of partner to be a strong risk factor for preeclampsia.

Various studies proposed that currently, there is no sure way to prevent preeclampsia. For many years diet has been suggested to play a role in preeclampsia. The hypotheses have been diverse and often mutually inconsistent. Most of the recommendation proposed by many studies are: increase the amount of fruit and vegetables and decrease the amount of fried foods and junk food, get enough rest, exercise regularly, avoid drinking alcohol, avoid beverages containing caffeine and taking folate and iron regularly [29] [30] [35] [52]. The result of this study also supports the above recommendation. For all women with preeclampsia, the potential benefits of a healthy diet and weight control cannot be overemphasized per se. Decisions about nutrition must carefully consider and incorporate the individual characteristics and circumstances of country's socioeconomic status.

\section{Conclusion}

With the target of the Millennium Development Goals in sight, preeclampsia/eclampsia needs to be identified as a priority area in reducing maternal mortality in developing countries. Since identification of the determinant factors will enhance the ability to diagnose and monitor women likely to develop preeclampsia before the onset of disease for timely interventions and better maternal and fetal outcomes, in view of our findings, there are several preventive and risk factors for preeclampsia. Vegetable and fruit consumption and folate intake during pregnancy are independent protective factors of preeclampsia. On the other hand, higher mid upper arm circumference, anemia and coffee intake during pregnancy are risk factors for the development of preeclampsia. It is recommended that these factors can be used as a screening tool for preeclampsia prediction and early diagnoses allowing timely interventions to be performed to minimize deaths associated with severe preeclampsia/eclampsia. Further research is needed to understand the effect of dosage and frequency of nutrient, alcohol and caffeine intake on incidence of preeclampsia.

\section{Limitation}

The findings of this study should be viewed in light of the following limitations. We might have introduced selection bias since cases were selected consecutively as they appear for diagnosis. The random and systematic measurement error in self-reported dietary intake might attenuate the association observed in this study. Dietary assessment was made at diagnosis hence, recall bias is inevitable. We did not also assess the effect of wide range of dietary factors on preeclampsia; therefore, causal relationship cannot be inferred from this case-control study.

\section{Acknowledgements}

The authors would like to thank Rift Valley University for sponsoring this study. We also extend our appreciations to Amhara Regional Health Bureau, Bahir Dar City Administration Health Office and its health facilities for facilitating the data collection process, and the study subjects for their keen participation. 


\section{Declaration of Competing Interest}

The authors declared they have no competing interest.

\section{Author Contribution}

Mulualem Endeshaw has contributed in the design, data collection, manuscript development and write up. Fekadu Ambaw has contributed in edition and revision of the final manuscript. Amanu Aragaw has participated in data analysis. Asrat Ayalew has contributed during data collection.

\section{References}

[1] Siddik-Sayyid, S.M. (2011) Preclampsia, a New Perspective. MEJ Anaesthesia, 21.

[2] Rath, W. and Fischer, T. (2008) Diagnosis, Evaluation, and Management of the Hypertensive Disorders of Pregnancy. Deutsches Ärzteblatt International, 106, 733-738.

[3] National High Blood Pressure Education Program Working Group on High Blood Pressure in Pregnancy (2000) Report of the National High Blood Pressure Education Program Working Group on High Blood Pressure in Pregnancy. American Journal of Obstetrics and Gynecology, 183, S1-S22. http://dx.doi.org/10.1067/mob.2000.107928

[4] Osungbade, K.O. and Ige, O.K. (2011) Public Health Perspectives of Preeclampsia in Developing Countries: Implication for Health System Strengthening. Journal of Pregnancy, 2011, Article ID: 481095. http://dx.doi.org/10.1155/2011/481095

[5] Lill, T., Per, M., Rolv, S. and Camilla, S. (2008) Previous Abortions and Risk of Preeclampsia. International Journal of Epidemiology, 37, 1333-1340. http://dx.doi.org/10.1093/ije/dyn167

[6] Roberts, M.J. and Gammill, H.S. (2005) Preeclampsia: Recent Insights. American Heart Association, 46, $1243-1249$.

[7] Duley, L. (2009) The Global Impact of Preeclampsia and Eclampsia. Seminars in Perinatology, 33, 130-137. http://dx.doi.org/10.1053/j.semperi.2009.02.010

[8] WHO (2011) Recommendations for Prevention and Treatment of Preeclampsia and Eclampsia. Department of Maternal and Child Health.

[9] Ngoc, N.T.N., Merialdi, M., Abdel-Aleem, H., Carroli, G., Purwar, M., Zavaleta, N., et al. (2011) Causes of Stillbirths and Early Neonatal Deaths: Data from 7993 Pregnancies in Six Developing Countries. Bulletin of the World Health Organization, 84, 699-705. http://dx.doi.org/10.2471/BLT.05.027300

[10] Polyzos, N.P., Polyzos, I.P., Zavos, A., Valachis, A., Mauri, D., Papanikolaou, E.G., Tzioras, S., Weber, D. and Messinis, I.E. (2010) Obstetric Outcomes after Treatment of Periodontal Disease during Pregnancy: Systematic Review and Meta-Analysis. BMJ, 341, c7017. http://dx.doi.org/10.1136/bmj.c7017

[11] Edmonds, D.K. (2007) Dewhurst’s Textbook of Obstetrics \& Gynaecology. Blackwell Publishing Asia Pty Ltd., Melbourne. http://dx.doi.org/10.1002/9780470753354

[12] Abdella, A. (2010) Maternal Mortality Trend in Ethiopia. Ethiopian Journal of Health Development, 24, 115-122.

[13] Owiredu, W., Ahenkorah, L., Turpin, C., Amidu, N. and Laing, E. (2012) Putative Risk Factors of Pregnancy-Induced Hypertension among Ghanaian Pregnant Women. Medical and Biomedical Sciences, 1, 62-76.

[14] Tebeu, P.M., Foumane, P., Mbu, R., Fosso, G., Biyaga, P.T. and Fomulu, J.N. (2011) Risk Factors for Hypertensive Disorders in Pregnancy: A Report from the Maroua Regional Hospital, Cameroon. Journal of Reproduction \& Infertility, 12, 227-234.

[15] Cnossen, J.S., Leeflang, M.M., de Haan, E.E., Mol, B.W., van der Post, J.A., Khan, K.S. and Ter Riet, G. (2007) Accuracy of Body Mass Index in Predicting Pre-Eclampsia: Bivariate Meta-Analysis. BJOG: An International Journal of Obstetrics \& Gynaecology, 114, 1477-1485. http://dx.doi.org/10.1111/j.1471-0528.2007.01483.x

[16] Wolf, M., Shah, A., Jiminizekimble, R., Sauk, J., Ecker, J. and Thadnai, R. (2004) Differential Risk of Hypertensive Disorders of Pregnancy among Hispanic Women. Journal of the American Society of Nephrology, 15, 1330-1338. http://dx.doi.org/10.1097/01.ASN.0000125615.35046.59

[17] Rasmussen, S. and Irgens, L.M. (2007) Pregnancy-Induced Hypertension in Women Who Were Born Small. Hypertension, 49, 806-812.

[18] Luo, B. and Ma, X. (2013) Risk Factors for Preeclampsia: A Case-Control Study. Hypertension in Pregnancy, 32, 432438.

[19] Rosenberg, T.J., Garbers, S., Lipkind, H. and Chiasson, M.A. (2005) Maternal Obesity and Diabetes as Risk Factors for Adverse Pregnancy Outcomes: Differences among 4 Racial/Ethnic Groups. American Journal of Public Health, 95, $1545-1551$. 
[20] Xiong, X., Buekens, P., Fraser, W.D., Beck, J. and Offenbacher, S. (2006) Periodontal Disease and Adverse Pregnancy Outcomes: A Systematic Review. BJOG: An International Journal of Obstetrics \& Gynaecology, 113, 135-143.

[21] Robillard, P.Y., Hulsey, T.C., Alexander, G.R., Keenan, A., de Caunes, F. and Papiernik, E. (1993) Paternity Patterns and Risk of Preeclampsia in the Last Pregnancy in Multiparae. Journal of Reproductive Immunology, 24, 1-12. http://dx.doi.org/10.1016/0165-0378(93)90032-D

[22] Agrawal, S. and Walia, G.K. (2010) Prevalence and Risk Factors for Pre-Eclampsia in Indian Women: A National Cross Sectional Study. South Asia Network for Chronic Disease, Public Health Foundation of India, New Delhi.

[23] Sibai, B., Dekker, G. and Baumert, M. (2005) Pre-Eclampsia. The Lancet, 365, 785-799. http://dx.doi.org/10.1016/S0140-6736(05)17987-2

[24] Qiu, C., Williams, M.A., Leisenring, W.M., Sorensen, T.K., Frederick, I.O., Dempsey, J.C. and Luthy, D.A. (2003) Family History of Hypertension and Type 2 Diabetes in Relation to Preeclampsia Risk. Hypertension, 41, 408-413.

[25] Brantsaeter, A.L., Haugen, M., Samuelsen, S.O., Torjusen, H., Trogstad, L., Alexander, J., et al. (2009) A Dietary Pattern Characterized by High Intake of Vegetables, Fruits, and Vegetable Oils Is Associated with Reduced Risk of Preeclampsia in Nulliparous Pregnant Norwegian Women. The Journal of Nutrition, 139, 1162-1168.

[26] Cynthia, V. and Max, W. (2001) Relationship of Twin Zygosity and Risk of Preeclampsia. American Journal of Obstetrics \& Gynecology, 185, 819-821. http://dx.doi.org/10.1067/mob.2001.117352

[27] Torjusen, H., Lieblein, G., Næs, T., Haugen, M., Meltzer, H.M. and Brantsæter, A.L. (2012) Food Patterns and Dietary Quality Associated with Organic Food Consumption during Pregnancy; Data from a Large Cohort of Pregnant Women in Norway. BMC Public Health, 12, 612. http://dx.doi.org/10.1186/1471-2458-12-612

[28] Wen, S.W., Champagne, J., White, R.R., Coyle, D., Fraser, W., Smith, G., Fergusson, D. and Walker, M.C. (2013) Effect of Folic Acid Supplementation in Pregnancy on Preeclampsia: The Folic Acid Clinical Trial Study. Journal of Pregnancy, 2013, Article ID: 294312.

[29] Schoenaker, D.A., Soedamah-Muthu, S.S. and Mishra, G.D. (2014) The Association between Dietary Factors and Gestational Hypertension and Pre-Eclampsia: A Systematic Review and Meta-Analysis of Observational Studies. BMC Medicine, 12, 157. http://dx.doi.org/10.1186/s12916-014-0157-7

[30] Torjusen, H., Brantsæter, A.L., Haugen, M., Alexander, J., Bakketeig, L.S., Lieblein, G., et al. (2014) Reduced Risk of Pre-Eclampsia with Organic Vegetable Consumption: Results from the Prospective Norwegian Mother and Child Cohort Study. BMJ Open, 4, Article ID: e006143. http://dx.doi.org/10.1136/bmjopen-2014-006143

[31] den Heijer, M., Koster, T., Blom, H., Bos, G.M.J., Briët, E., Reitsma, P.H., et al. (1996) Hyperhomocysteinemia as a Risk Factor for Deep-Vein Thrombosis. England Journal of Medicine, 334, 759-762.

[32] Fanga, R., Dawsona, A., Lohsoonthorna, V. and Williamsa, M.A. (2009) Risk Factors of Early and Late Onset Preeclampsia among Thai Women. Asian Biomedicine, 3, 477-486.

[33] Meltzer, H.M., Brantsæter, A.L., Nilsen, R.M., Magnus, P., Alexander, J. and Haugen, M. (2011) Effect of Dietary Factors in Pregnancy on Risk of Pregnancy Complications: Results from the Norwegian Mother and Child Cohort Study. American Journal of Clinical Nutrition, 94, 1970S-1974S. http://dx.doi.org/10.3945/ajcn.110.001248

[34] den Heijer, M., Koster, T., Blom, H.J., Bos, G.M., Briet, E., Reitsma, P.H., Vandenbroucke, J.P. and Rosendaal, F.R.. (1996) Hyperhomocysteinemia as a Risk Factor for Deep-Vein Thrombosis. New England Journal of Medicine, 334, 759-762. http://dx.doi.org/10.1056/NEJM199603213341203

[35] Dodd, J.M., O’Brien, C. and Grivell, R.M. (2014) Preventing Pre-Eclampsia-Are Dietary Factors the Key? BMC Medicine, 12, 176. http://dx.doi.org/10.1186/s12916-014-0176-4

[36] Bakker, W.W., Donker, R.B., Timmer, A., van Pampus, M.G., van Son, W.J., Aarnoudse, J.G., et al. (2007) Plasma Hemopexin Activity in Pregnancy and Preeclampsia. Hypertension in Pregnancy, 26, 227-239. http://dx.doi.org/10.1080/10641950701274896

[37] Yakub, M., Iqbal, M.P. and Iqbal, R. (2010) Dietary Patterns Are Associated with Hyperhomocysteinemia in an Urban Pakistani Population. The Journal of Nutrition, 140, 1261-1266. http://dx.doi.org/10.3945/jn.109.120477

[38] Haberg, S., London, S., Stigum, H., Nafstad, P. and Nystad, W. (2009) Folic Acid Supplements in Pregnancy and Early Childhood Respiratory Health. Archives of Disease in Childhood, 94, 180-184. http://dx.doi.org/10.1136/adc.2008.142448

[39] Modder, J. and Fitzsimons, K. (2010) Management of Women with Obesity in Pregnancy. Centre for Maternal and Child Enquiries (CMACE) and the Royal College of Obstetricians and Gynaecologists (RCOG) Joint Guideline.

[40] Mahomed, K., Williams, M.A., Woelk, G.B., Jenkins-Woelk, L., Mudzamiri, S., Longstaff, L. and Sorensen, T.K. (1998) Risk Factors for Pre-Eclampsia among Zimbabwean Women: Maternal Arm Circumference and Other Anthropometric Measures of Obesity. Paediatric and Perinatal Epidemiology, 12, 253-262.

[41] Derbyshire, E. (2009) Can Anthropometric and Body Composition Measurements during Pregnancy Be Used to Pre- 
dict Preeclampsia Risk? Current Women’s Health Reviews, 5, 225-229. http://dx.doi.org/10.2174/157340409790069934

[42] Silva, D.A.S., Petroski, E.L. and Peres, M.A. (2012) Is High Body Fat Estimated by Body Mass Index and Waist Circumference a Predictor of Hypertension in Adults? A Population-Based Study. Nutrition Journal, 11, 112. http://dx.doi.org/10.1186/1475-2891-11-112

[43] Ali, A.A., Rayis, D.A., Abdallah, T.M., Elbashir, M.I. and Adam, I. (2011) Severe Anaemia Is Associated with a Higher Risk for Preeclampsia and Poor Perinatal Outcomes in Kassala Hospital, Eastern Sudan. BMC Research Notes, 4, 311.

[44] Rohilla, M., Raveendran, A., Dhaliwal, L.K. and Chopra, S. (2010) Severe Anaemia in Pregnancy: A Tertiary Hospital Experience from Northern India. Journal of Obstetrics and Gynaecology, 30, 694-696. http://dx.doi.org/10.3109/01443615.2010.509821

[45] Lee, A.I. and Okam, M.M. (2011) Anemia in Pregnancy. Hematology/Oncology Clinics of North America, 25, $241-259$. http://dx.doi.org/10.1016/j.hoc.2011.02.001

[46] Spaans, F., de Vos, P., Bakker, W.W., van Goor, H. and Faas, M.M. (2014) Danger Signals from ATP and Adenosine in Pregnancy and Preeclampsia. Hypertension, 63, 1154-1160.

[47] Sharbaf, F.R., Dehghanpour, P., Shariat, M. and Dalili, H. (2013) Caffeine Consumption and Incidence of Hypertension in Pregnancy. Journal of Family and Reproductive Health, 7, 3.

[48] Bakker, R., Steegers, E.A., Obradov, A., Raat, H., Hofman, A. and Jaddoe, V.W. (2010) Maternal Caffeine Intake from Coffee and Tea, Fetal Growth, and the Risks of Adverse Birth Outcomes: The Generation R Study. The American Journal of Clinical Nutrition, 91, 1691-1698. http://dx.doi.org/10.3945/ajcn.2009.28792

[49] Shamsi, U., Hatcher, J., Shamsi, A., Zuberi, N., Qadri, Z. and Saleem, S. (2010) A Multicenter Matched Case Control Study of Risk Factors for Preeclampsia in Healthy Women in Pakistan. BMC Women's Health, 10, 14. http://dx.doi.org/10.1186/1472-6874-10-14

[50] Zenebe, W., Hailemariam, S. and Mirkuzie, W. (2011) Hypertensive Disorders of Pregnancy in Jimma University Specialized Hospital. Ethiopian Journal of Health Sciences, 21, 147-154.

[51] Lardoeyt, R., Vargas, G., Lumpuy, J., García, R. and Torres, Y. (2013) Contribution of Genome-Environment Interaction to Pre-Eclampsia in a Havana Maternity Hospital. MEDICC Review, 15, 22-29.

[52] McCarthy, F., O’Keeffe, L. and Khashan, A. (2013) Association between Maternal Alcohol Consumption in Early Pregnancy and Pregnancy Outcomes. Obstetrics and Gynecology, 122, 830-837. http://dx.doi.org/10.1097/AOG.0b013e3182a6b226 
Scientific Research Publishing (SCIRP) is one of the largest Open Access journal publishers. It is currently publishing more than 200 open access, online, peer-reviewed journals covering a wide range of academic disciplines. SCIRP serves the worldwide academic communities and contributes to the progress and application of science with its publication.

Other selected journals from SCIRP are listed as below. Submit your manuscript to us via either submit@scirp.org or Online Submission Portal.
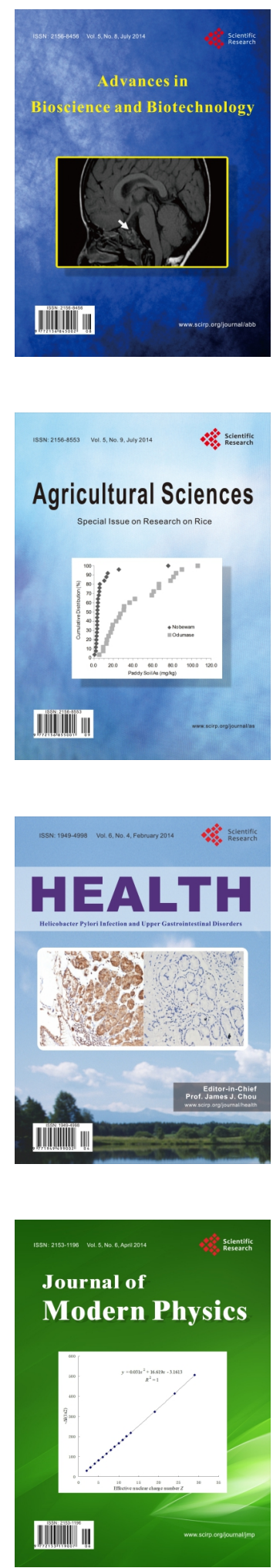
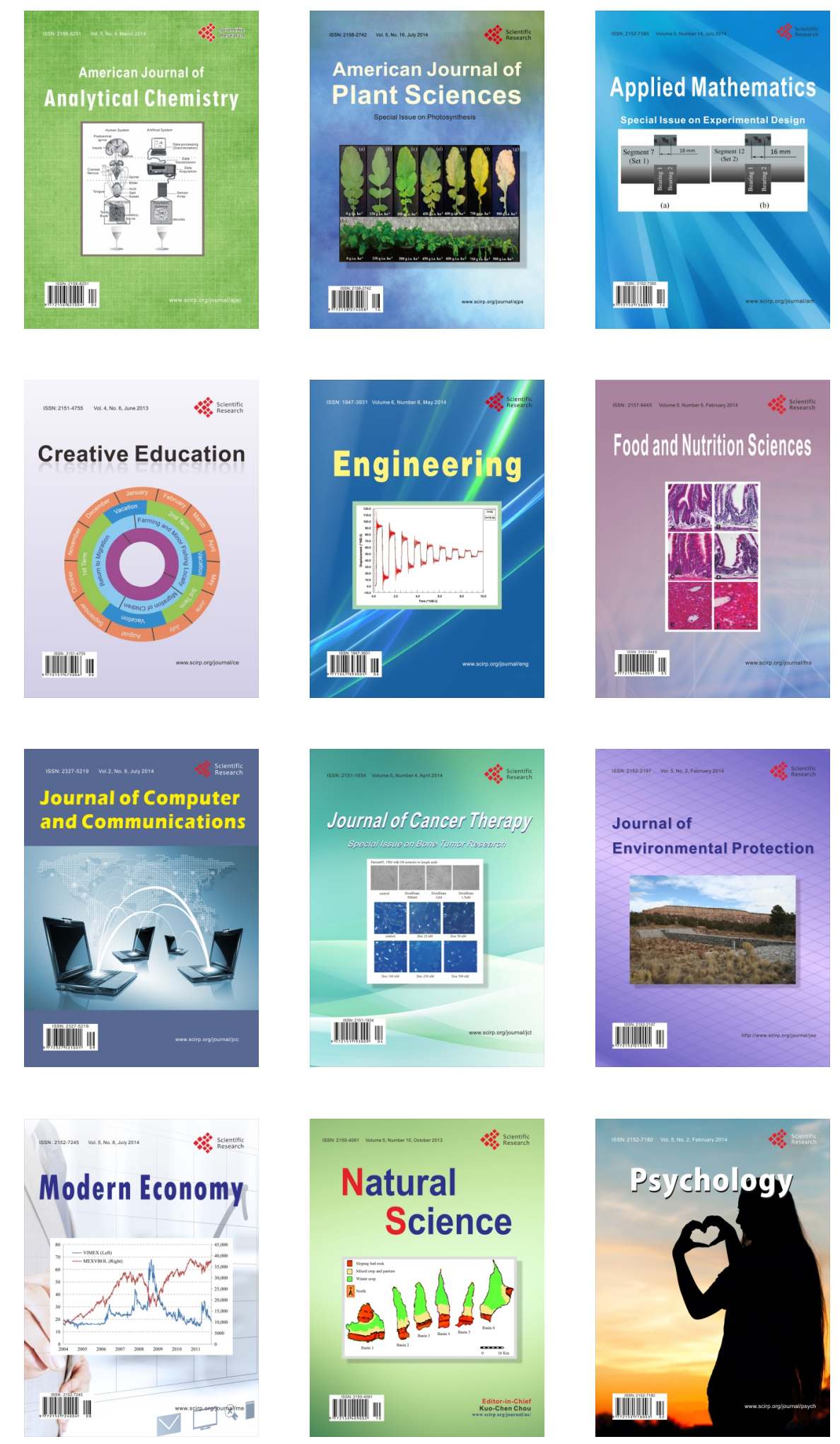